\title{
Cost-effectiveness of eplerenone in NYHA class II chronic heart failure patients with reduced LVEF: an analysis for Greece
}

This article was published in the following Dove Press journal:

ClinicoEconomics and Outcomes Research

12 October 2016

Number of times this article has been viewed

\author{
Kostas Athanasakis' \\ Aikaterini Bilitou ${ }^{2}$ \\ Dawn Lee ${ }^{3}$ \\ Eleftheria Karampli' \\ Apostolos Karavidas ${ }^{4}$ \\ John Parissis ${ }^{5}$ \\ Georgia Sykara ${ }^{2}$ \\ John Kyriopoulos'
}

'Department of Health Economics, National School of Public Health,

Athens, Greece; ${ }^{2}$ Pfizer Hellas,

Athens, Greece; ${ }^{3}$ BresMed, Sheffield,

UK; ${ }^{4}$ Department of Cardiology, G.

Gennimatas Hospital, Athens, Greece;

${ }^{5}$ Heart Failure Unit, Department

of Cardiology, Athens University

Hospital Attikon, National and

Kapodistrian University of Athens, Athens, Greece
Correspondence: Aikaterini Bilitou Pfizer Hellas SA, 243 Messogion Avenue,

I545I, Athens, Greece

Tel +30 2l 06785883

Fax +30 2I 06748680

Email Katerina.bilitou@pfizer.com
Objectives: The aim of the study was to evaluate the cost-effectiveness (CE) of treatment with eplerenone versus standard care in adult patients with New York Heart Association class II chronic heart failure and reduced left ventricular ejection fraction from the perspective of the Greek national health care payer.

Methods: A discrete-event model simulating the clinical course and respective outcomes of eplerenone as an add-on to standard therapy versus standard therapy alone based on the pivotal Eplerenone in Mild Patients Hospitalization and SurvIval Study in Heart Failure (EMPHASISHF) trial was locally adapted for the Greek setting. Data on medications followed the resource use from eplerenone in mild patients hospitalization and survival study in heart failure and were estimated on a lifetime basis (or until discontinuation). Cost calculations were based on year 2014, event costs (cardiovascular hospitalizations, adverse events, and devices) were sourced from published diagnosis-related groups. A 3\% discount rate was applied. In order to test the robustness of the model projections, a range of deterministic and probabilistic sensitivity analyses were carried out.

Results: Over a patient's lifetime, the addition of eplerenone to standard care compared to standard care alone led to an incremental gain of 1.33 quality-adjusted life-years (QALYs) (6.53 vs 5.20 QALYs, respectively) as well as an increase in the cost of treatment by $€ 2,160$; these outcomes produced an incremental CE ratio of $€ 1,624 / \mathrm{QALY}$ for the Greek setting. On the basis of probabilistic sensitivity analysis, there was a $100 \%$ likelihood of eplerenone being cost-effective versus standard care at a threshold of $€ 3,500 / \mathrm{QALY}$.

Conclusion: This analysis indicates that eplerenone may be a cost-effective option versus standard care accompanied by additional clinical benefits and an added incremental cost at an acceptable, if not low, CE ratio. The results are consistent with the previously published studies on the CE of eplerenone as an add-on therapy to standard care, such as those regarding the health care settings of Spain, the UK, and Australia.

Keywords: heart failure, eplerenone, cost-effectiveness, EMPHASIS-HF, Greece

\section{Introduction}

Heart failure (HF) represents a major public health issue with a complex pathology and disease management pattern as well as high prevalence. ${ }^{1,2}$ About $1 \%-2 \%$ of the adult population in developed countries suffer from $\mathrm{HF}$, with this percentage rising to over $10 \%$ when it comes to individuals aged 65 years or older. ${ }^{3-6}$ Although mortality rates have declined in the recent years, ${ }^{7-9}$ HF-related hospitalizations have substantially increased in the last decade, representing 1\%-2\% of all hospital admissions and becoming the leading reason for admission in individuals aged 65 years or older. ${ }^{6}$ 
Moreover, readmission rates are quite high, ranging between $25 \%$ and $30 \%$ at 3 months and about $50 \%$ at 6 months postdischarge. ${ }^{10,11}$ Consequently, HF significantly impacts health care budgets internationally, with hospitalization admissions accounting for the most substantial part of this burden. ${ }^{12-14}$ Apart from the in-hospital part of patient management, the complexity of HF as a clinical problem and the associated comorbidities contributing to the progression of the disease and thus higher hospitalization rates and polypharmacy, lead to a subsequent and continuous increase in expenditures attributed to $\mathrm{HF}^{15-17}$

A key objective in HF management is, therefore, to alleviate symptoms, reduce the occurrence and need for hospitalizations, and, subsequently, increase survival and improve the patients' quality of life..$^{5,18,19}$ Treatment options such as angiotensin-converting enzyme inhibitors and beta blockers, although effective in some aspects of the treatment, have not yet shown the desired outcomes in terms of clinical efficacy. ${ }^{5,18,19}$ In this light, newer and emerging treatments could play a role in the future of patient management and improved clinical results. Among those, eplerenone, a selective mineralocorticoid-receptor antagonist, also known as an aldosterone antagonist, has been indicated for patients with New York Heart Association (NYHA) class II chronic heart failure (CHF) with reduced left ventricular ejection fraction (LVEF), in addition to standard therapy, on the basis of improved clinical outcomes, that is, reduced cardiovascular (CV) mortality and morbidity, in adult patients with NYHA class II CHF and left ventricular systolic dysfunction (LVEF $\leq 30 \%)^{20,21}$

The implementation of adequate and sustainable health policies, particularly when considering conditions with significant prevalence and large expenditure such as CHF, seems imperative at a time when health resources are becoming even scarcer and health care systems have to allocate them in the most efficient way. In order to achieve these objectives, economic evaluation methods are indispensable tools in the decision-making process.

The aim of this study was to evaluate the cost-effectiveness (CE) of treatment with eplerenone in adult patients with NYHA class II CHF and reduced LVEF in Greece, from the perspective of a health care system at a time under severe financial constraints and austerity.

\section{Methods}

\section{Health economic model}

A discrete-event simulation economic model constructed on the basis of the reported outcomes of a pivotal study of eplerenone, the Eplerenone in Mild Patients Hospitalization and SurvIval Study in Heart Failure (EMPHASIS-HF) trial, ${ }^{21}$ and previously published ${ }^{22}$ was locally adapted for the Greek health care setting.

The purpose of the model was to simulate the clinical course and respective outcomes over a patient's lifetime of two treatment alternatives: eplerenone as per trial protocol, starting dose of $25 \mathrm{mg}$ once daily increased at 4 weeks to $50 \mathrm{mg}$ once daily as an add-on to standard therapy versus standard therapy alone (Figure 1).

Patient population in the model follows the demographic and clinical characteristics of patients in the EMPHASIS-HF trial, ${ }^{21}$ that is, all patients were NYHA class II, had a mean age of 69 years, had a mean LVEF of $26 \%$, and $78 \%$ of patients were male. Concomitant medication usage was reported at trial enrollment and as per trial protocol, subjects were to remain on the same dosing throughout the trial duration; ${ }^{21}$ it was therefore assumed that subjects remained on the same pharmacotherapy for their lifetime ( $85 \%$ treated with diuretics, 78\% with angiotensin-converting enzyme inhibitors, $19 \%$ with angiotensin receptors blockers, $87 \%$ with beta blockers, $88 \%$ with antithrombotics including antiplatelet or oral anticoagulants, and $63 \%$ with lipid-lowering agents). ${ }^{21}$

Figure 1 illustrates the outline of the model and patient flows/projections. ${ }^{22}$ In brief, individual times to events are assigned to each simulated patient for each model event. One identical patient is "cloned" and follows each treatment arm. Probabilities of future events are estimated based on risk equations for each event derived from patient-level data from EMPHASIS-HF (time-dependent distributions). ${ }^{21}$ Thus, treatment efficacy is a factor that influences the occurrence and time of occurrence of a series of events such as HF hospitalization, other CV hospitalization, new-onset atrial fibrillation, implantation of cardiac resynchronization therapy (CRT) or implantable cardioverter defibrillator (ICD) devices, adverse events, discontinuation of eplerenone, CV mortality, and other causes of mortality, all of which were recorded in the EMPHASIS-HF trial. Patients remain in the model until death occurs, or are given an ICD or CRT device. The model accurately projects the withintrial outcomes; ${ }^{22}$ for the time beyond the trial follow-up period, the model also provides a reasonable approximation of current survival estimates for chronic systolic HF patients, with a mean survival of approximately 8 years in the standard care arm.

The model calculates the resource use associated with treatment: drug costs of active treatment and concomitant medications, disease monitoring and disease-related events. 


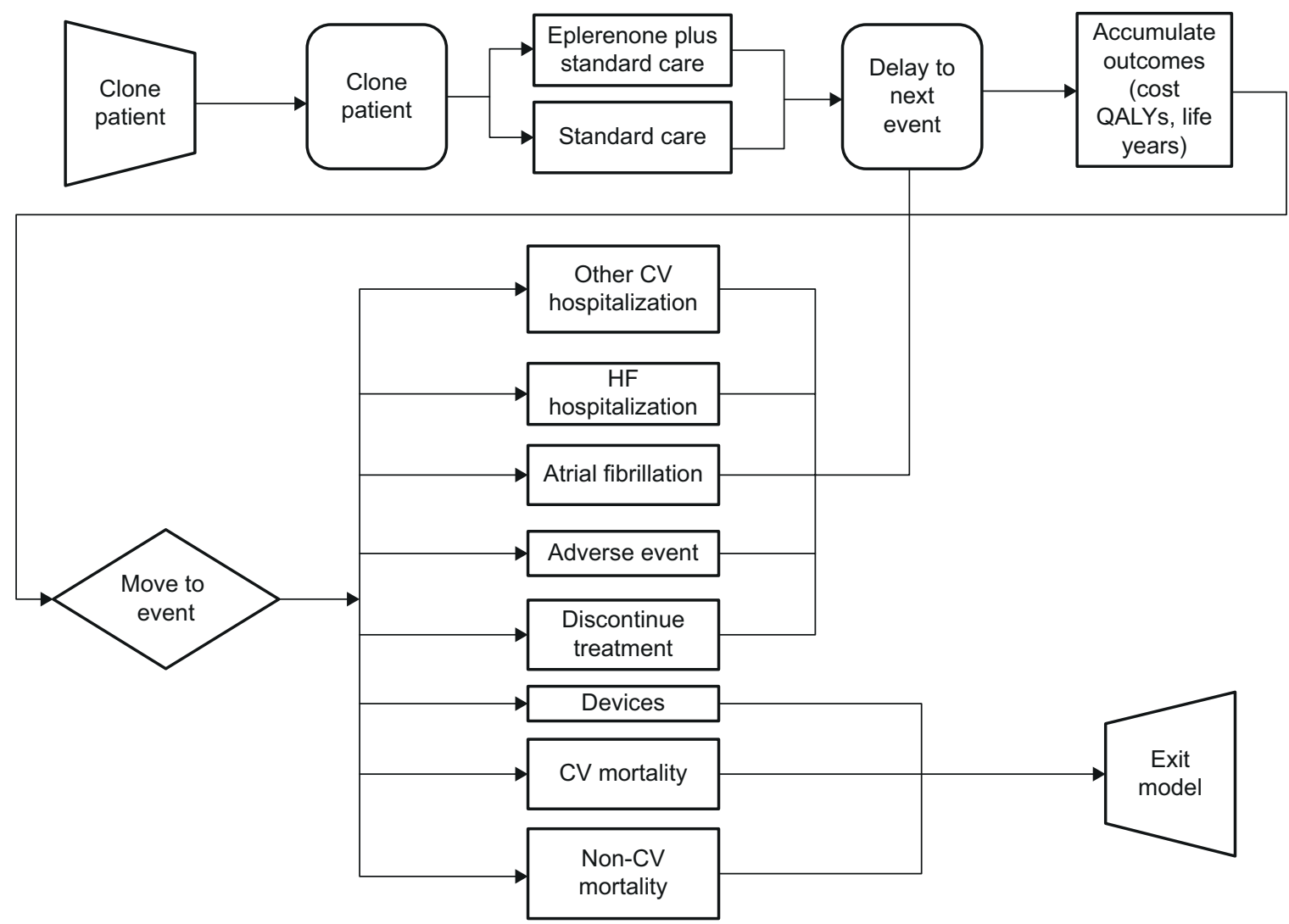

Figure I Model structure.

Note: Reproduced from Heart, Lee D, Wilson K, Akehurst R, et al, Cost-effectiveness of eplerenone in patients with systolic heart failure and mild symptoms, I00(2I), 168I-1687, (C) 2014 with permission from BMJ Publishing Group Ltd. ${ }^{22}$

Abbreviations: CV, cardiovascular; HF, heart failure; QALYs, quality-adjusted life-years.

Moreover, based on the clinical outcomes of treatment, health-related quality of life estimations in the form of utilities were also employed as described previously ${ }^{22}$ and also shown in Table 1.

Treatment discontinuations were taken from the EMPHASIS-HF trial, using the proportions of patients discontinuing after each type of event. ${ }^{22}$ Time to event was based on probabilistic distributions and outcomes were accumulated for 25,000 patients for each arm.

\section{Model inputs}

The analysis adopts the perspective of a third-party payer, the largest social security fund in Greece and, thus, calculates only direct resource use and costs (inpatient and outpatient). With regards to cost inputs, prices and diagnosis-related group tariffs were sourced from publicly available sources, ${ }^{23,24}$ or published literature ${ }^{25}$ (Table 1). Data on medications follow the resource use from the EMPHASIS-HF, and are estimated on a lifetime basis (or until discontinuation). ${ }^{21}$ Event costs (sourced from published diagnosis-related groups) represent the acute phase (in case of hospitalization) and do not contain follow-up costs. Model structure and inputs on resource use were verified by two clinical experts from the Greek health care setting. The costs for events (CV hospitalizations, adverse events, and devices) were based upon the proportion of patients experiencing each of those events in the EMPHASIS-HF trial. Cost of devices refers to the cost of medical procedure for the application of the device as well as the cost of the device itself. Due to nonavailability of a reliable estimate, the cost of death was not included in the model as a conservative assumption. Cost calculations were based on year 2014, ${ }^{23,24}$ and a $3 \%$ discount rate was applied.

Utility values were taken from published literature and, specifically, calculated using the utility formula from Göhler et ${ }^{26}{ }^{26}$ using the baseline characteristics of the patients within the EMPHASIS-HF trial. The occurrence of events was accompanied by a decrement, proportional to the severity of the event. ${ }^{27-29}$ The utility values used within the model are summarized in Table 1.

The remaining life span and quality of life for patients receiving ICD or CRT devices were calculated using the hazard ratios (compared to standard care treatment as within the placebo arm of the trial) provided previously. ${ }^{30}$ 
Table I Inputs for medication, event costs, and utilities used within the model (input values for the base case and sensitivity analysis are shown)

\begin{tabular}{|c|c|c|c|c|}
\hline \multirow{2}{*}{\multicolumn{2}{|c|}{$\begin{array}{ll}\text { Parameter } & \text { Input value } \\
\text { Annual intervention costs (average per patient) }\end{array}$}} & \multicolumn{2}{|c|}{ Distribution, upper and lower bound used in sensitivity analysis } & \multirow[t]{2}{*}{ Source } \\
\hline & & & & \\
\hline Eplerenone & $€ 260.92$ & Fixed & - & 24 \\
\hline Concomitant medications & $€ 283.38$ & $\begin{array}{l}\text { Costs varied using uniform distribution using } \mathrm{min} / \\
\text { max of available drug brands or } \pm 30 \% \text { where only } \\
\text { one brand is available }\end{array}$ & $€|63.17-€ 924.6|$ & 24 \\
\hline Disease management ${ }^{\mathrm{a}}$ & $€ 40.00$ & Gamma distribution assuming SD $10 \%$ of mean & $€ 32.00-€ 48.00$ & 39 \\
\hline \multicolumn{5}{|l|}{ Event-based costs } \\
\hline Heart failure hospitalization & $€ 3,198.00$ & Gamma distribution SD $€ 3,260$ & $€|49-€ 9,7| 2$ & 25 \\
\hline Other CV hospitalizations & $€ 1,281.36$ & Gamma distribution assuming SD $10 \%$ of mean & $€ 768.65-€ 2,076.5 \mathrm{I}$ & 23 \\
\hline Adverse events - eplerenone ${ }^{b}$ & $€ 104.53$ & & $€ 87.95-€ \mid 22.30$ & \\
\hline Adverse events - placebob & $€ 156.70$ & & $€|3| .84-€ \mid 83.33$ & \\
\hline $\begin{array}{l}\text { Cost of progression (weighted average of } \\
\text { CRT and ICD devices) }\end{array}$ & $€ 12,753.60$ & & $€|0,730.79-€| 4,92 \mid .35$ & \\
\hline Average device life & 5.8 years & $\begin{array}{l}\text { Uniform distribution using min and max of } \\
\text { sources }\end{array}$ & 3.1 years- -8.6 years & 30 \\
\hline \multicolumn{5}{|l|}{ Quality-of life-utilities } \\
\hline Baseline utility & 0.84 & Beta distribution using the SD from the source & 0.77 to 0.90 & 26 \\
\hline $\begin{array}{l}\text { Utility decrement for patients who } \\
\text { experience one hospitalization }\end{array}$ & -0.024 & & -0.013 to -0.036 & \\
\hline $\begin{array}{l}\text { Utility decrement for patients who } \\
\text { experience two hospitalizations }\end{array}$ & -0.031 & & -0.017 to -0.047 & \\
\hline $\begin{array}{l}\text { Utility decrement for patients who } \\
\text { experience three hospitalizations }\end{array}$ & -0.055 & & -0.048 to -0.057 & \\
\hline $\begin{array}{l}\text { Utility decrement for new-onset atrial } \\
\text { fibrillation }\end{array}$ & -0.084 & Uniform distribution $\pm 30 \%$ & -0.059 to -0.109 & 27 \\
\hline $\begin{array}{l}\text { Lifetime utility decrement for adverse } \\
\text { events - eplerenone }\end{array}$ & -0.0003 & & -0.00021 to -0.00039 & 29 \\
\hline $\begin{array}{l}\text { Lifetime utility decrement for adverse } \\
\text { events - placebo }\end{array}$ & -0.0001 & & -0.00007 to -0.00013 & \\
\hline $\begin{array}{l}\text { Short-term utility decrement for adverse } \\
\text { events - eplerenone }{ }^{c}\end{array}$ & -0.0012 & & -0.00084 to -0.00156 & 28,29 \\
\hline $\begin{array}{l}\text { Short-term utility decrement for adverse } \\
\text { events - placebo }{ }^{c}\end{array}$ & -0.0008 & & -0.00056 to -0.00104 & \\
\hline
\end{tabular}

Notes: ${ }^{a}$ Based on an average of four cardiology visits per year based on expert opinion, 'Only costs for renal failure were included in the adverse events category, since all other adverse events were assumed to have zero cost based upon the Greek tariffs. Costs are higher in the placebo arm as more patients experienced renal failure, which is costly, 'Applied for 21 days based upon clinician advice as per Lee et al. ${ }^{22}$

Abbreviations: CRT, cardiac resynchronization therapy; CV, cardiovascular; ICD, implantable cardioverter defibrillator.

\section{Sensitivity analysis}

Where possible, information on uncertainty was obtained from the publication used for model inputs or directly from clinical trial data. ${ }^{21,22}$ Costs were modeled using a gamma distribution, utilities, and proportions using a beta distribution. Uniform distributions were used where maximum and minimum values were given within the literature and the applicability of a mean value within the range was uncertain. Upper and lower bound limits of inputs as well as type of distribution used in the sensitivity analysis are shown in Table 1. In order to test the robustness of the model projections, a range of deterministic sensitivity analyses was carried out by varying a number of scenario parameters within their likely range (95\% confidence intervals) (Figure 2).
In addition to the above, a probabilistic sensitivity analysis (PSA) was also performed. In the PSA, inputs for times to events, costs, and utility values were assigned a probability distribution and were stochastically varied. Outcomes were produced via a Monte Carlo simulation method with 100 iterations.

\section{Results}

Table 2 presents the discounted results of the analysis. Over a patient's lifetime, the addition of eplerenone to standard care versus standard care alone led to an incremental gain of 1.33 quality-adjusted life-years (QALYs) (6.53 vs 5.20 QALYs, respectively) as well as an increase in the cost of treatment by $€ 2,160$. These outcomes produced an incremental costeffectiveness ratio (ICER) of $€ 1,624 / \mathrm{QALY}$ for the Greek setting. 


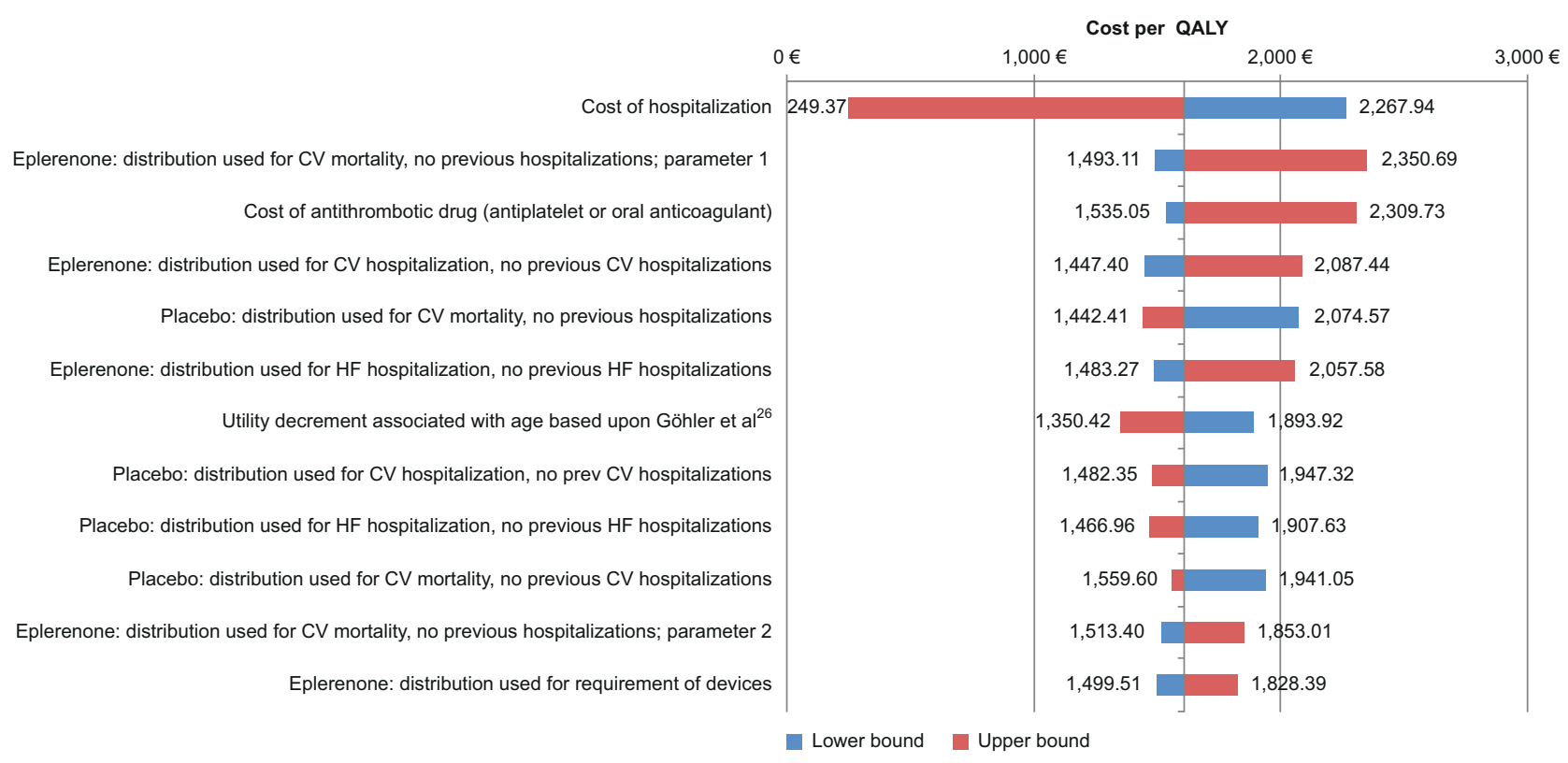

Figure 2 Tornado diagram of deterministic sensitivity analysis.

Abbreviations: CV, cardiovascular; HF, heart failure; QALY, quality-adjusted life-year.

Table 2 Base case results from the discrete event simulation model (discounted)

\begin{tabular}{|c|c|c|c|c|c|}
\hline Treatment & Costs & QALYs & $\begin{array}{l}\text { Life } \\
\text { years }\end{array}$ & ICER & Cost/LY \\
\hline Eplerenone & $€ \mid 4,628$ & 6.53 & 8.18 & $€ I, 624 /$ & $€ I, 30 I$ \\
\hline $\begin{array}{l}\text { Standard of } \\
\text { care }\end{array}$ & $€ \mid 2,468$ & 5.20 & 6.52 & QALY & \\
\hline
\end{tabular}

Abbreviations: ICER, incremental cost-effectiveness ratio; LY, life year; QALYs, quality-adjusted life-year.

Table 3 Cost results from the discrete event simulation model (€, discounted)

\begin{tabular}{|c|c|c|c|}
\hline Costs $(€)$ & Eplerenone & Standard care & Incremental \\
\hline CV hospitalizations & 1,413 & 1,409 & 4 \\
\hline HF hospitalizations & 3,675 & 4,572 & -898 \\
\hline Eplerenone treatment & 1,678 & 0 & 1,678 \\
\hline $\begin{array}{l}\text { Concomitant } \\
\text { treatment }\end{array}$ & 2,317 & $\mathrm{I}, 847$ & 47I \\
\hline Devices & 5,156 & 4,318 & 839 \\
\hline Disease management & 327 & 261 & 66 \\
\hline Adverse events & 62 & 61 & 1 \\
\hline Total cost & 14,628 & 12,468 & 2,160 \\
\hline
\end{tabular}

Note: Numbers may not add up due to rounding. Abbreviations: $\mathrm{CV}$, cardiovascular; $\mathrm{HF}$, heart failure.

Table 3 shows a breakdown of the costs for each treatment arm for the Greek setting based on the model adaptation. The main differences in costs between treatment strategies are seen in the costs associated with HF hospitalizations, which are lower in the case of eplerenone; the costs of devices; and the cost of pharmacotherapy; this may be partly due to the extended life expectancy of those receiving eplerenone versus standard therapy ( 8.18 vs 6.52 life years, discounted).

The results of the deterministic sensitivity analyses are presented in Figure 2. It can be seen from the Tornado plots that the most sensitive model parameters are, in particular, the cost of HF-related hospitalization, as well as the distributional parameters for CV mortality when no previous hospitalizations have been experienced, and the cost of antithrombotic drug used (antiplatelet or oral anticoagulant). Nevertheless, the model seemed robust in its predictions and the results remained favorable for eplerenone in the analysis undertaken.

Similarly, probabilistic analyses conducted imply robustness of the model (Figure 3). The probabilistic iterations of the model demonstrate that, in all cases, eplerenone provides a QALY benefit over standard care (overall mean ICER of $€ 1,896)$. The ICERs are well below an acceptability threshold range of $£ 20,000-£ 30,000 /$ QALY gained (based on the upper and lower acceptability thresholds used in the National Institute for Health and Care Excellence guidance for economic evaluations ${ }^{31}$ ), although no explicit criterion of willingness to pay exists for Greece and much debate exists globally around CE threshold policy. ${ }^{32,33}$

As shown in Figure 4, eplerenone was a cost-effective treatment choice compared to standard care in $100 \%$ of the iterations for any threshold over $€ 3,500 / \mathrm{QALY}$ gained.

\section{Discussion}

This analysis aimed at evaluating the clinicoeconomic value of adding eplerenone to the standard therapy of adult 


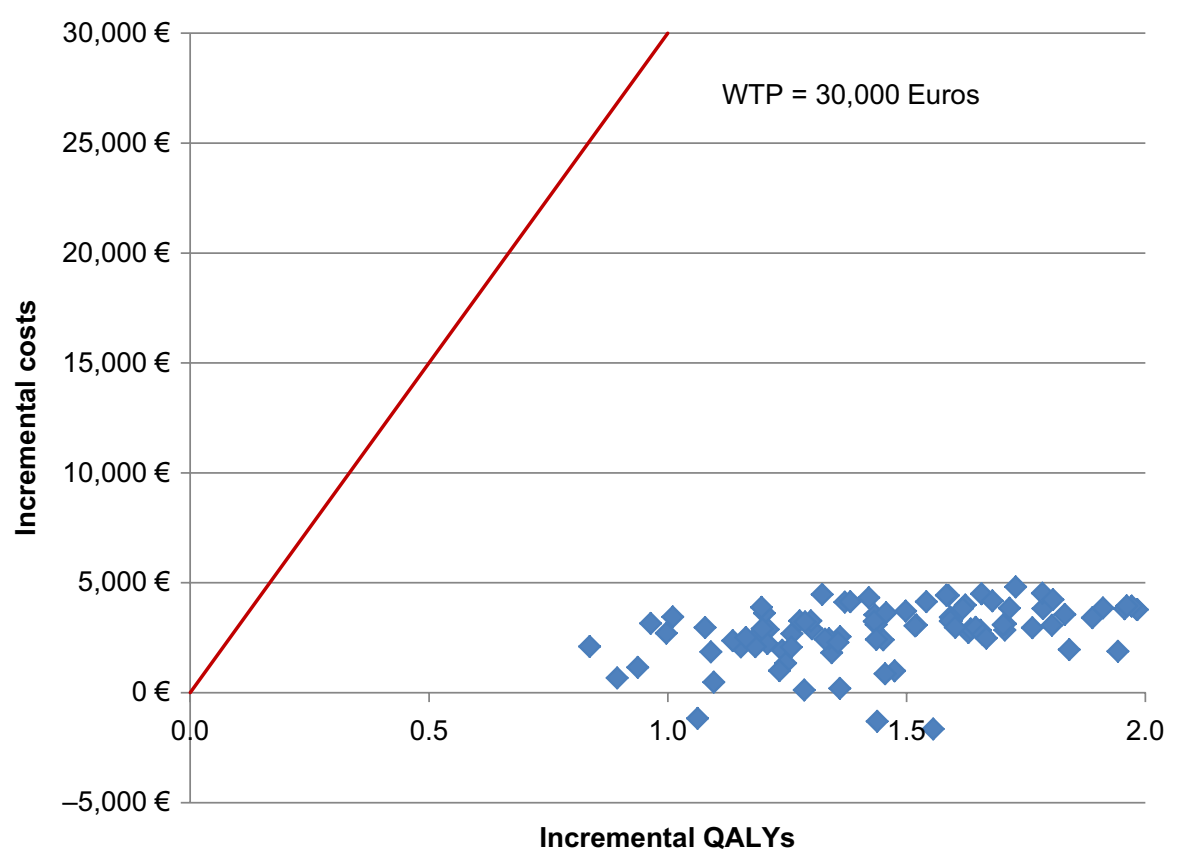

Figure 3 Scatter plot of incremental quality-adjusted life expectancy and lifetime costs for eplerenone vs placebo (the red line represents the threshold of WTP at $€ 30,000$ ). Abbreviations: QALYs, quality-adjusted life-year; WTP, willingness-to-pay.

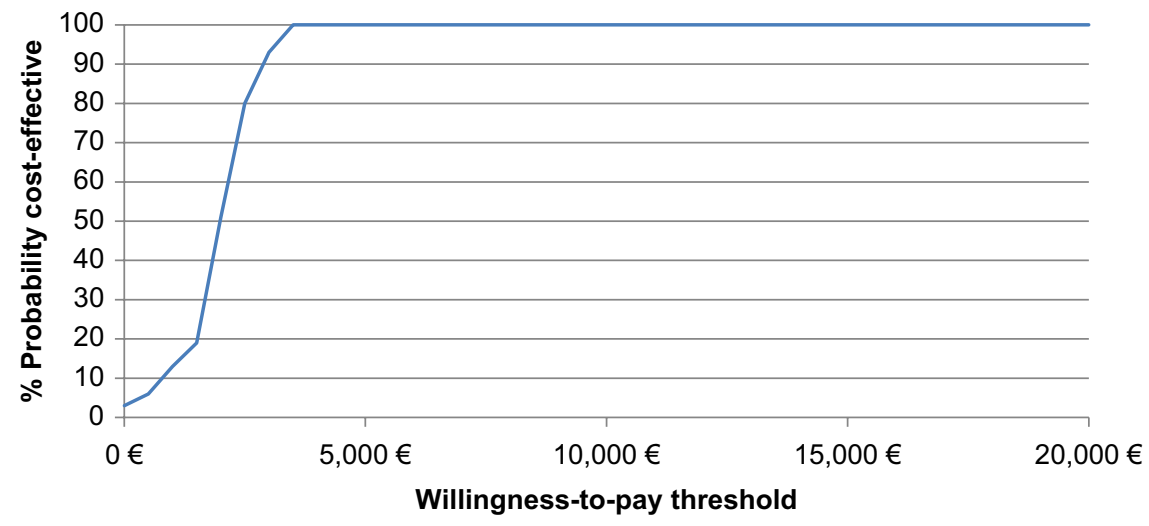

Figure 4 Cost-effectiveness acceptability curve for eplerenone vs standard care.

patients with NYHA class II HF and reduced LVEF in a setting characterized by severe constraints and deep austerity and contractionary measures. The results of the evaluation indicate that under the present analysis, eplerenone represents a cost-effective option vs standard care accompanied by additional clinical benefit and an added incremental cost at an acceptable, if not low, cost-effectiveness ratio. The core results proved to be rather robust to a series of one-way sensitivity analyses. On the basis of a PSA approach, there was a $100 \%$ likelihood of eplerenone being cost-effective versus standard care at a threshold of $€ 3,500 / \mathrm{Q} A L Y$.

The present results are consistent with the previously published studies on the $\mathrm{CE}$ of eplerenone as an add-on therapy to standard care, such as those regarding the health care settings of Spain, ${ }^{22}$ the UK, ${ }^{22}$ and Australia, ${ }^{34}$ on the basis of clinical efficacy data from the EMPHASIS-HF trial and, also, for the US, ${ }^{35}$ France, ${ }^{36}$ Switzerland, ${ }^{37}$ and the Netherlands ${ }^{38}$ based on clinical efficacy data from the Eplerenone Post-Acute Myocardial Infarction Heart Failure Efficacy and Survival Study (EPHESUS) trial ${ }^{39}$ referring to a different study population than the one used in this analysis - namely patients with HF after recent myocardial infarction.

As with any study of this kind, the present one is subject to some limitations that should be acknowledged. First of all, a limitation arises from the fact that the study population, for reasons of consistency and ability to compare the results at an international level, follows the characteristics of the population of the EMPHASIS-HF trial. This could suggest that a discrepancy of the characteristics of the study population and the actual population of Greek HF patients could 
exist. However, the multicenter nature of the trial with Greek patients also enrolled and the fact that the characteristics of the patients enrolled in EMPHASIS-HF are not dissimilar to typical well-treated patients seen in hospital practice (inpatient or outpatient) across Europe ${ }^{1,40}$ could suggest that those discrepancies are not to a notable extent. Moreover, the results of the extensive sensitivity analysis suggest that even if there were notable differences, they would produce a rather negligible effect on the main tendency of outcomes (favorable CE).

Another limitation of the analysis stems from the fact that it is performed using a third-party payer perspective, that is, the perspective of social insurance. A third-party payer perspective does not include costs to society, mainly the productivity losses as a result of the disease and the costs of informal care. The latter could constitute an important cost variable, especially for patients whose daily activities are severely impaired by the CV events associated with HF. Inclusion of such costs typically favors the treatment that averts most clinical events, compared to alternatives, whereas exclusion of societal costs constitutes a conservative approach for the most efficacious alternative (in this case, eplerenone).

Finally, as the EMPHASIS-HF trial was stopped early, due to the evidence of early benefit in the eplerenone-treated arm compared to the standard of care population, there could be some uncertainty regarding the long-term outcomes of eplerenone in the available clinical data. This uncertainty in the clinical data has, however, been included within the modeling approach used and examined within both probabilistic and deterministic sensitivity analyses and has also been discussed and addressed in other economic evaluations of eplerenone that source their efficacy data from EMPHASIS$\mathrm{HF}$ (indicatively, Lee et $\mathrm{al}^{22}$ ).

In an era of scarce resources and ever-increasing health care needs, rational allocation of resources is an absolute necessity. In this decision-making process, $\mathrm{CE}$ analysis can be a useful tool in an attempt to quantify both the clinical benefits as well as the costs associated with each treatment option. Based on this line of thought, the present analysis aimed to evaluate the costs and effects of the addition of a newer treatment option for patients with NYHA class II chronic HF to the current standard of care and concluded that this intervention is a cost-effective option within the Greek context.

\section{Acknowledgments}

The authors would like to thank Becky Pennington for her original work on developing the economic model, as well as John Vincent and Katharina Lins for their valuable comments on improving the manuscript.

\section{Author contributions}

All authors made substantial contributions to conception and design, acquisition of data, or analysis and interpretation of data; took part in drafting the article or revising it critically for important intellectual content; gave final approval of the version to be published; and agree to be accountable for all aspects of the work.

\section{Disclosure}

DL is an employee of BresMed and was a paid consultant to Pfizer in connection with the sensitivity analysis and development of this manuscript. AB and GS are employees of Pfizer Hellas. The authors report no other conflicts of interest in this work.

\section{References}

1. Cleland JG, Swedberg K, Follath F, et al. The EuroHeart Failure survey programme - a survey on the quality of care among patients with heart failure in Europe. Part 1: patient characteristics and diagnosis. Eur Heart J. 2003;24(5):442-463.

2. Heidenreich PA, Albert NM, Allen LA, et al. Forecasting the impact of heart failure in the United States: a policy statement from the American Heart Association. Circ Heart Fail. 2013;6(3):606-619.

3. Azad N, Lemay G. Management of chronic heart failure in the older population. J Geriatr Cardiol. 2014;11(4):329-337.

4. Masoudi FA, Havranek EP, Krumholz HM. The burden of chronic congestive heart failure in older persons: magnitude and implications for policy and research. Heart Fail Rev. 2002;7(1):9-16.

5. McMurray JJ, Adamopoulos S, Anker SD, et al. ESC guidelines for the diagnosis and treatment of acute and chronic heart failure 2012: the task force for the diagnosis and treatment of acute and chronic heart failure 2012 of the European Society of Cardiology. Developed in collaboration with the Heart Failure Association (HFA) of the ESC. Eur J Heart Fail. 2012; 14(8):803-869.

6. Zannad F, Agrinier N, Alla F. Heart failure burden and therapy. Europace. 2009;11 Suppl 5:v1-v9.

7. Cowie MR, WoodDA, CoatsAJ,Thompson SG, SureshV,Poole-Wilson PA, Sutton GC. Survival of patients with a new diagnosis of heart failure: a population based study. Heart. 2000;83(5):505-510.

8. Hobbs FD, Roalfe AK, Davis RC, Davies MK, Hare R; Midlands Research Practices Consortium (MidReC). Prognosis of all-cause heart failure and borderline left ventricular systolic dysfunction: 5 year mortality follow-up of the Echocardiographic Heart of England Screening Study (ECHOES). Eur Heart J. 2007;28(9):1128-1134.

9. Richard Hobbs FD. Clinical burden and health service challenges of chronic heart failure. Br J Gen Pract. 2010;60(577):611-615.

10. Filippatos G, Farmakis D, Bistola V, Karavidas A, Mebazaa A, Maggioni AP, Parissis JT. Temporal trends in epidemiology, clinical presentation and management of acute heart failure: results from the Greek cohorts of the Acute Heart Failure Global Registry of Standard Treatment and the European Society of Cardiology-Heart Failure pilot survey. Eur Heart J Acute Cardiovasc Care. Epub 2014 Mar 4.

11. Giamouzis G, Kalogeropoulos A, Georgiopoulou V, et al. Hospitalization epidemic in patients with heart failure: risk factors, risk prediction, knowledge gaps, and future directions. J Card Fail. 2011;17(1):54-75.

12. Ambrosy AP, Fonarow GC, Butler J, et al. The global health and economic burden of hospitalizations for heart failure: lessons learned from hospitalized heart failure registries. J Am Coll Cardiol. 2014;63(12): $1123-1133$.

13. Lee WC, Chavez YE, Baker T, Luce BR. Economic burden of heart failure: a summary of recent literature. Heart Lung. 2004;33(6): 362-371. 
14. Stewart S, Jenkins A, Buchan S, McGuire A, Capewell S, McMurray JJ. The current cost of heart failure to the National Health Service in the UK. Eur J Heart Fail. 2002;4(3):361-371.

15. Chong VH, Singh J, Parry H, Saunders J, Chowdhury F, Mancini DM, Lang CC. Management of non-cardiac comorbidities in chronic heart failure. Cardiovasc Ther. 2015;33(5):300-315.

16. Cook C, Cole G, Asaria P, Jabbour R, Francis DP. The annual global economic burden of heart failure. Int J Cardiol. 2014;171(3):368-376.

17. Lang CC, Mancini DM. Non-cardiac comorbidities in chronic heart failure. Heart. 2007;93(6):665-671.

18. Gandhi PU, Pinney S. Management of chronic heart failure: biomarkers, monitors, and disease management programs. Ann Glob Health. 2014; 80(1):46-54.

19. Williams RP, Oakeshott P. Diagnosis and management of chronic heart failure. BMJ. 2014;348:g1429.

20. National Organization for Medicines. Summary of Product Characteristics: Inspra 50mg/tab. Greece, 2015. Available from: http://services.eof. gr/drugsearch/block/resource/Mjk1MTU5OTIy/SPC_2650002_3.pdf. Accessed May 10, 2015.

21. Zannad F, McMurray JJ, Krum H, et al. Eplerenone in patients with systolic heart failure and mild symptoms. NEngl JMed. 2011;364(1):11-21.

22. Lee D, Wilson K, Akehurst R, et al. Cost-effectiveness of eplerenone in patients with systolic heart failure and mild symptoms. Heart. 2014;100(21):1681-1687.

23. Official Government Gazette of Greece, Issue B, Number 946, March 27, 2012. [Diagnostic Related Groups].

24. Official Government Gazette of Greece, Issue B, Number 2336, August 29, 2014. [Positive list of reimbursed medicines].

25. Parissis J, Athanasakis K, Farmakis D, et al. Determinants of the direct cost of heart failure hospitalization in a public tertiary hospital. Int $J$ Cardiol. 2015;180:46-49.

26. Göhler A, Geisler BP, Manne JM, et al. Utility estimates for decisionanalytic modeling in chronic heart failure - health states based on New York Heart Association classes and number of rehospitalizations. Value Health. 2009;12(1):185-187.

27. Berg J, Lindgren P, Nieuwlaat R, Bouin O, Crijns H. Factors determining utility measured with the EQ-5D in patients with atrial fibrillation. Qual Life Res. 2010;19(3):381-390.

28. Mowatt G, Vale L, Perez J, et al. Systematic review of the effectiveness and cost-effectiveness, and economic evaluation, of home versus hospital or satellite unit haemodialysis for people with end-stage renal failure. Health Technol Assess. 2003;7(2):1-174.

29. Sullivan PW, Slejko JF, Sculpher MJ, Ghushchyan V. Catalogue of EQ-5D scores for the United Kingdom. Med Decis Making. 2011;31(6): $800-804$.
30. Fox M, Mealing S, Anderson R, Dean J, Stein K, Price A, Taylor RS. The clinical effectiveness and cost-effectiveness of cardiac resynchronisation (biventricular pacing) for heart failure: systematic review and economic model. Health Technol Assess. 2007;11(47):iiiiv, ix-248.

31. NICE. Guide to the Methods of Technology Appraisal 2014. Available from: http://www.nice.org.uk/article/pmg9/resources/non-guidanceguide-to-the-methods-of-technology-appraisal-2013-pdf; 2013. Accessed May 10, 2015.

32. Eichler HG, Kong SX, Gerth WC, Mavros P, Jonsson B. Use of cost-effectiveness analysis in health-care resource allocation decision-making: how are cost-effectiveness thresholds expected to emerge? Value Health. 2004;7(5):518-528.

33. Nimdet K, Chaiyakunapruk N, Vichansavakul K, Ngorsuraches S. A systematic review of studies eliciting willingness-to-pay per qualityadjusted life year: does it justify CE threshold? PLoS One. 2015; 10(4): 0122760.

34. Ademi Z, Pasupathi K, Krum H, Liew D. Cost effectiveness of eplerenone in patients with chronic heart failure. Am J Cardiovasc Drugs. 2014; 14(3):209-216.

35. Zhang Z, Mahoney EM, Kolm P, Spertus J, Caro J, Willke R, Weintraub WS. Cost effectiveness of eplerenone in patients with heart failure after acute myocardial infarction who were taking both ACE inhibitors and beta-blockers: subanalysis of the EPHESUS. Am J Cardiovasc Drugs. 2010;10(1):55-63.

36. de Pouvourville G, Solesse A, Beillat M. Cost-effectiveness analysis of aldosterone blockade with eplerenone in patients with heart failure after acute myocardial infarction in the French context: the EPHESUS study. Arch Cardiovasc Dis. 2008;101(9):515-521.

37. Szucs TD, Holm MV, Schwenkglenks M, Zhang Z, Weintraub WS, Burnier M, Erne P. Cost-effectiveness of eplerenone in patients with left ventricular dysfunction after myocardial infarction - an analysis of the EPHESUS study from a Swiss perspective. Cardiovasc Drugs Ther. 2006;20(3):193-204.

38. van Genugten ML, Weintraub WS, Zhang Z, Voors AA. Cost-effectiveness of eplerenone plus standard treatment compared with standard treatment in patients with myocardial infarction complicated by left ventricular systolic dysfunction and heart failure in the Netherlands. Neth Heart J. 2005;13(11):393-400.

39. Pitt B, Remme W, Zannad F, et al. Eplerenone, a selective aldosterone blocker, in patients with left ventricular dysfunction after myocardial infarction. N Engl J Med. 2003;348(14):1309-1321.

40. NICOR. National Heart Failure Audit. Available from: http://www. hqip.org.uk/assets/NCAPOP-Library/Heart-Failure-Audit-ReportNICOR-2010-2011.pdf. 2012. Accessed May 10, 2015.
ClinicoEconomics and Outcomes Research

\section{Publish your work in this journal}

ClinicoEconomics and Outcomes Research is an international, peerreviewed open-access journal focusing on health technology assessment, pharmacoeconomics and outcomes research in the areas of diagnosis, medical devices, and clinical, surgical and pharmacological intervention. The economic impact of health policy and health systems

\section{Dovepress}

organization also constitute important areas of coverage. The manuscript management system is completely online and includes a very quick and fair peer-review system, which is all easy to use. Visit http://www.dovepress.com/testimonials.php to read real quotes from published authors. 